\title{
Water Use, Growth, and Fruit Yield of 'Hosui' Asian Pears under Deficit Irrigation
}

\author{
Horst W. Caspari' ${ }^{1}$ M. Hossein Behboudian², and David J. Chalmers ${ }^{3}$ \\ Department of Plant Science, Massey University, Palmerston North, New Zealand \\ Additional index words. Pyrus serotina, Nashi, irrigation, lysimetry
}

\begin{abstract}
Five-year old 'Hosui' Asian pear (Pyrus serotina Rehder) trees growing in drainage lysimeters and trained onto a Tatura trellis were subjected to three different irrigation regimes. Weekly water use (WU) was calculated using the massbalance approach. Soil-water content of control lysimeters was kept at pot capacity, while deficit irrigation was applied before [regulated deficit irrigation (RDI)] and during the period of rapid fruit growth [late deficit irrigation (LDI)]. Soil-water content was maintained at $\approx \mathbf{5 0 \%}$ and $\mathbf{7 5 \%}$ of pot capacity for RDI and LDI, respectively. Deficit irrigation reduced mean WU during RDI and LDI by $20 \%$. The reduced WU was caused by lower stomatal conductance $\left(\mathrm{g}_{\mathrm{s}}\right)$ on deficit-irrigated trees. RDI trees had more-negative diurnal leaf water potentials $\left(\psi_{1}\right)$. The $\psi_{1}, \mathrm{~g}_{\mathrm{s}}$, and WU remained lower for 2 weeks after RDI was discontinued. RDI reduced shoot extension and summer pruning weights, whereas winter pruning weights were not different between treatments. Except for the final week of RDI, fruit growth was not reduced, and fruit from RDI grew faster than the control during the first week after RDI. In contrast, fruit volume measurements showed that fruit growth was clearly inhibited by LDI. Final fruit size and yield, however, were not different between treatments. Return bloom was reduced by RDI but was not affected by LDI.
\end{abstract}

Regulated deficit irrigation (RDI) (Chalmers et al., 1981) has been developed as an irrigation management approach to control tree growth. Deficit irrigation applied before rapid fruit growth commences has been used successfully to reduce tree growth without deleterious effects on fruit growth and flowering in 'Golden Queen' peaches [Prunus persica (L.) Batsch] (Chalmers et al., 1981), 'Bartlett' pears (Pyrus communis L.) (Mitchell et al., 1984), and 'Gala' apples (Malus domestica Borkh.) (Durand, 1990). RDI conserves irrigation water (Mitchell and Chalmers, 1982; Mitchell et al., 1989), although the mechanisms have not been identified. Tree water use (WU) depends strongly on the stomatal conductance $\left(\mathrm{g}_{\mathrm{s}}\right)$ of individual leaves and the leaf area index. The $\mathrm{g}_{\mathrm{s}}$, which is very sensitive to soil-water deficit (Downton et al., 1987; Flore et al., 1985; Higgs and Jones, 1990; Tan and Buttery, 1982), provides the dominant short-term physiological control over transpiration; leaf area, which can be very sensitive to stress during rapid canopy growth in spring (Landsberg and Jones, 1981), can be important for controlling long-term WU (Jones et al., 1985).

We have been interested in applying deficit irrigation to control vegetative growth of Asian pear, especially for the vigorous cultivar Hosui. For this cultivar, up to four shoot growth flushes have been observed during one season. Shoot growth generally ceases during the period of rapid fruit growth, restarting after harvest. 'Hosui' fruit growth follows a sigmoidal pattern, with $\approx 60 \%$ of final fruit weight accumulated in the last 4 weeks before harvest. A short-term water deficit did not affect 'Hosui' fruit growth when applied during the period of slow fruit growth, when shoots were growing vigorously, but inhibited fruit growth when applied during the final stages of fruit growth (Caspari et al., 1993a). This relatively clear separation between vegetative and

Received for publication 1 Feb. 1993. Accepted for publication 10 June 1993. Mention of trade names does not constitute a guarantee or warranty of the products by Massey Univ. nor does it imply endorsement of similar commercial products. The cost of publishing this paper was defrayed in part by the payment of page charges. Under postal regulations, this paper therefore must be hereby marked advertisement solely to indicate this fact.

${ }^{1}$ Visiting scientist supported by a grant from Gottlieb Daimler-und Karl Benz-Stiftung, Ladenburg, Federal Republic of Germany. Current address: HortResearch, Marlborough Research Centre, Private Bag 1007, Blenheim, New Zealand. ${ }^{2}$ Senior lecturer.

${ }^{3}$ Professor. Current address: 13 Valleyside Drive, Crafers, SA 5152, Australia. fruit growth resembles results with 'Golden Queen' peaches (Mitchell and Chalmers, 1982) and 'Bartlett' pears (Mitchell et al., 1984), indicating that deficit-irrigation techniques may be applied to control shoot growth of Asian pears without detrimental effects on fruit growth and yield.

A study was initiated to determine whether deficit irrigation could be used to control vigor of 'Hosui' Asian pears. A soil-water deficit during the early stages of fruit growth (RDI) was compared to a deficit during the final stages [late deficit irrigation(LDI)], and the effects of these water deficits on WU, $g_{s}$, growth, and fruit yield were evaluated.

\section{Materials and Methods}

Experimental conditions. The experiment was situated at the lysimeter facility of Massey Univ. near Palmerston North, New Zealand (lat. $40.2^{\circ} \mathrm{S}$, long. $175.4^{\circ} \mathrm{E}$ ). A detailed description of installation and operation of the lysimeter facility is given in Chalmers et al. (1992).

Briefly, the facility consists of a row of 12 drainage lysimeters, each $0.785 \mathrm{~m}^{3}$ of soil, situated within a 1.1-ha block of Asian pears. The dimensions of each lysimeter vessel provide a $1.2-\mathrm{m}$ tree spacing within row for the single trees contained therein. The rows of the orchard are $5 \mathrm{~m}$ apart; soil management consists of mown grass with a 2-m-wide herbicide strip along the tree line.

One Asian pear tree, 'Hosui', grafted on Pyrus serotina seedling rootstock, was planted in each of the lysimeters in Sept. 1987 and trained onto a Tatura trellis (Chalmers et al., 1978). Irrigation and fertilization was applied to each tree via a closed nutrient-feed system from two 9100-liter tanks. The lysimeters were covered with a reflective, opaque plastic cover to minimize rainfall entry and soil evaporation. The lysimeter facility was managed and monitored automatically with a multi-tasking controller-datalogger (Wormald 1830, Christchurch, New Zealand).

Soil moisture measurements. An access tube for a neutron moisture meter was placed $0.2 \mathrm{~m}$ from the tree trunk in each lysimeter. A neutron hydroprobe (model 503DR; CPN Corp., Martinez, Calif.) was used to take measurements twice weekly at 0.2-m-deep intervals from 0.2 to $1.0 \mathrm{~m}$ beneath the soil surface. The neutron hydroprobe was calibrated by the method of Campbell and Campbell (1982). Soil-water content (in mm) was obtained by 
multiplying the volumetric soil-water content $\left(\mathrm{m}^{3} \cdot \mathrm{m}^{-3}\right)$ by soil layer depth in $\mathrm{mm}(300,200,200,200$, and 100 for the $0.2,0.4,0.6$, 0.8 , and $1.0-\mathrm{m}$ measurement depths, respectively). Soil-water content was converted to liters by multiplying total soil-water content by $0.785 \mathrm{~m}^{2} /$ lysimeter, since $1 \mathrm{~mm}=1$ liter $\cdot \mathrm{m}^{-2}$. Pot capacity was defined as the soil-moisture content (in liters) when drainage from the lysimeters had ceased, $\approx 24 \mathrm{~h}$ after irrigation.

Irrigation regime. Initially (from early Sept. 1991), all trees were irrigated every third day to replace WU by the trees and return the soil moisture to pot capacity. Starting 42 days after full bloom (dafb), two different irrigation regimes were applied. Eight trees, the control treatment, were irrigated as described above. The remaining four trees, the RDI treatment, were irrigated at the same times receiving $33 \%$ of the irrigation volume applied to the control. After soil-water storage in the driest RDI lysimeter had fallen to $\approx 50 \%$ of pot capacity, the irrigation volumes for the RDI treatment were adjusted to keep soil water at about this level. At the estimated start of rapid fruit growth, the deficit-irrigated trees were rewatered to return soil moisture to pot capacity (115 dafb). Thereafter, RDI trees were irrigated as for the control.

Four of the eight control trees were used to investigate the effect of a moderate water deficit on fruit growth in the final stages of fruit development. This LDI treatment started 126 dafb. Initially, trees were irrigated at $50 \%$ of control. After the soil moisture had fallen to $\approx 75 \%$ of pot capacity, irrigation was adjusted to keep soil moisture at this level. Trees were returned to full irrigation after the last harvest (159 dafb).

Meteorological measurements. Evaporation data $\left(\mathrm{E}_{\mathrm{pan}}\right)$ were obtained from a Class A pan located $\approx 1 \mathrm{~km}$ from the lysimeter facility.

Tree $W U$. WU was calculated using an appropriate form of the conservation of water equation (Sharma, 1985), as WU $=\mathrm{I}+\Delta \mathrm{W}$ $-\mathrm{D}$, where $\mathrm{I}$ is irrigation, $\Delta \mathrm{W}$ is the change in soil-water storage, and $\mathrm{D}$ is drainage.

Plant measurements. The first flowers opened at the end of Aug. 1991, but full bloom, when $>95 \%$ of flowers had opened, was not until 14 Sept. The fruit were thinned 28 dafb to one fruit per cluster and thinned a second time 53 dafb to $\approx 18$ fruit $/ \mathrm{m}^{2}$ canopy surface area (CSA). The changes in fruit volume were calculated from weekly measurements of maximum fruit diameter of at least 11 labeled fruit/tree, commencing 52 dafb. Fruit volume was estimated using the linear regression equation described previously (Caspari et al., 1993a). The first fruit were harvested 150 $\mathrm{dafb}$, with a second and final harvest $158 \mathrm{dafb}$. At harvest, the total weight of all fruit was recorded.

Diurnal changes in leaf water potential $\left(\psi_{1}\right)$ were measured on several days using a Scholander pressure bomb (Soilmoisture Equipment Corp., Santa Barbara, Calif.). Leaf $g_{s}$ was measured on the lower surface of fully expanded, sunlit leaves with a transit-time porometer (model Mk3; Delta-T Devices, Cambridge, U.K.). At least two $\left(\psi_{1}\right)$ and four $\left(\mathrm{g}_{\mathrm{s}}\right)$ samples per tree were taken for each measurement.

Shoot length was measured once a week on three control and three RDI trees, from 52 to 111 dafb. All trees were summer pruned $111 \mathrm{dafb}$, and pruning weights were recorded for each tree. The winter pruning weight of the current season's growth was recorded for each tree. Trunk circumference was measured $\approx 0.1 \mathrm{~m}$ above the graft union on all trees once a week.

CSA of each tree was calculated by summing the area of four rectangles, two on either side of the Tatura trellis, which best represented the canopy outline in the plane of the trellis. Mean CSA at the start and end of the season was $4.36 \mathrm{~m}^{2}$ and $4.99 \mathrm{~m}^{2}$, respectively. Mean projected groundcover, i.e., the area estimated to be covered by evaporating plant canopy, was $3.1 \mathrm{~m}^{2}$. At the start of the experiment, the average tree size (CSA) was similar for all treatments.

All trees were defoliated just before the onset of natural leaf drop ( $215 \mathrm{dafb}$ ). The total leaf area of each tree was estimated by measuring the leaf area of a subsample equivalent to $\approx 15 \%$ of total leaf fresh weight using a leaf area meter (model 3100; LI-COR, Lincoln, Neb.).

Statistical design and analysis. Each treatment consisted of four trees. Treatments were completely randomly allocated to trees of similar size (based on CSA). Due to low transpiration by the smallest RDI tree, the soil-moisture content never fell below 95\% of pot capacity. Therefore this tree was excluded from the analysis. Data were analyzed by the general linear model procedure (SAS Institute, 1985).

\section{Results}

$W U$. The lysimeters enabled a precise control of the soil-water status during the 1991-92 season (Fig. 1). The control treatment was maintained at or above pot capacity throughout the season. Within 3 weeks of RDI, the mean soil-water content in the RDI lysimeters had fallen to $\approx 60 \%$ of pot capacity and was kept between $50 \%$ and $60 \%$ of pot capacity until full irrigation was resumed. Similarly, during LDI, mean soil-water storage for LDI lysimeters was maintained at $\approx 70 \%$ to $80 \%$ of pot capacity.

The pattern of seasonal WU of well-watered Asian pears (Fig. 2) was similar to that reported for the 1990-91 season (Caspari et al., 1993a). Mean daily WU increased from $\approx 1$ liter/tree $(\approx 0.2$ liter $\left.\cdot \mathrm{m}^{-2} \mathrm{CSA}\right)$ after flowering to $\approx 10$ liters/tree $\left(\approx 2.2\right.$ liters $\cdot \mathrm{m}^{-2}$ CSA) at the end of January (135 dafb). Thereafter tree transpiration gradually declined. Seasonal WU was 1070 liters/tree $(\approx 234$ liters $\cdot \mathrm{m}^{-2} \mathrm{CSA}$ ), while $\mathrm{E}_{\mathrm{pan}}$ was $710 \mathrm{~mm}$. The correlation coefficient between weekly WU and $\mathrm{E}_{\mathrm{pan}}$ was $0.68(\mathrm{n}=29)$. Weekly $\mathrm{E}_{\mathrm{pan}}$ and WU data were used to calculate crop coefficients, so that $\mathrm{k}_{\mathrm{c}}^{\text {pan }}=$ $\mathrm{WU} / \mathrm{E}_{\mathrm{pan}}$. When calculated based on CSA or the projected ground area of the trees, these coefficients ranged from 0.09 to 0.63 and 0.12 to 0.94 , respectively. Their averages for the season were 0.33 and 0.49 , respectively. Similar values were also obtained for the previous season (Caspari et al., 1993a).

At the start of the season, there were no significant differences in tree WU between treatments until the start of RDI (Fig. 2). RDI

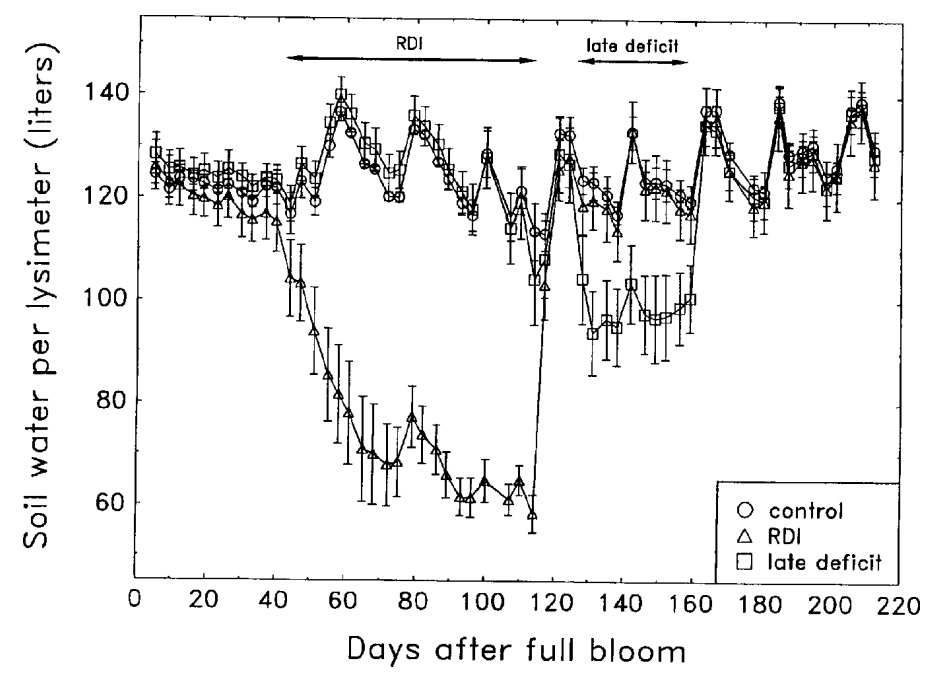

Fig. 1. Effect of irrigation regime on mean soil-water content per lysimeter during the 1991-92 season. Bars represent twice the SE of the means. 


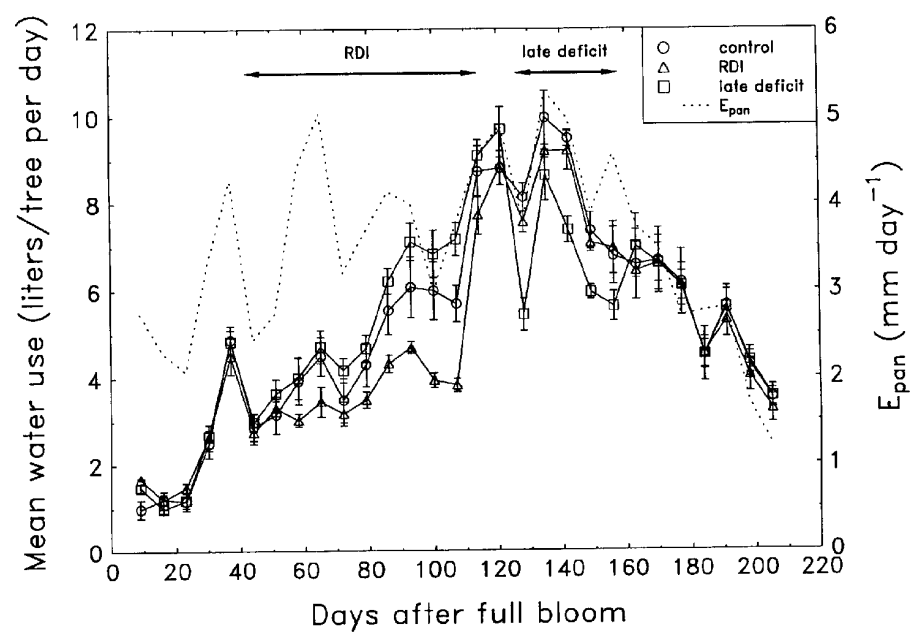

Fig. 2. Effect of irrigation regime on mean daily water use of 'Hosui' Asian pear trees grown in lysimeters with $\mathrm{E}_{\mathrm{pan}}$ values for 23 Sept. 1991 to 6 Apr. 1992 (9 to 205 days after full bloom). Bars represent twice the SE of the means.

significantly reduced WU. These differences in transpiration between well-watered and deficit-irrigated trees became more pronounced toward the end of the RDI period due to increases in leaf areas and higher evaporative demand. The WU calculated from the conservation of water equation was validated by measurements of instantaneous transpiration using the heat-pulse technique (data not shown). During RDI, deficit-irrigated trees used on average $20 \%$ less water than control trees. Once full irrigation was resumed, WU of RDI trees increased rapidly but, nevertheless, tended to be lower than the control for the first 4 weeks thereafter (114 to 142 dafb).

Soil-water content declined rapidly in the LDI lysimeters when trees were irrigated at $50 \%$ of control (Fig. 1). The reduced soil-water storage caused a significantly lower tree transpiration (Fig. 2), averaging only $79 \%$ of the control for LDI. After trees were returned to full irrigation, WU increased again to levels similar to the control.

Water relations. RDI significantly reduced $\mathrm{g}_{\mathrm{s}}$ (Fig. 3). In general, $g_{s}$ of well-watered trees increased during the morning, reaching a maximum before solar noon. Thereafter, $g_{s}$ would gradually decline, sometimes recovering during late afternoon. The $g_{s}$ of deficit-irrigated trees, however, tended to be highest during early morning and then decreased through most of the day (Fig. 3 a and b). During the first 2 weeks after rewatering, $g_{s}$ was still significantly lower on previous RDI trees, at least for parts of the day. Mean $g_{s}$ of RDI trees 8 days after rewatering (123 dafb) was 4.2 and $5.3 \mathrm{~mm} \cdot \mathrm{s}^{-1}$ at 13:00 and 14:30 $\mathrm{HR}$, respectively, compared to 5.5 and $6.5 \mathrm{~mm} \cdot \mathrm{s}^{-1}$ for the control. Two weeks after rewatering, lower $g_{s}$ values were measured on RDI trees during the morning, with no differences to the control for most of the day, but with higher $g$ values for the last measurement (Fig. 3c).

Similarly, LDI lowered $\mathrm{g}_{\mathrm{s}}$. Four days after the start of LDI (130 dafb), $g_{s}$ was similar to the control for the first two readings in the morning but significantly lower for the rest of the day (Fig. 3c).

There were no differences in $\psi_{1}$ between treatments for $\approx 2$ weeks after the start of RDI. Thereafter, predawn $\psi_{1}$ was lower on RDI trees, which was followed by a more-rapid decline in $\psi_{1}$ during the morning and a slower recovery during late afternoon. The diurnal course of $\psi_{1}$ during 2 typical days is shown in Fig. 4. Increasing cloud cover during late morning of 18 Nov. 1991 (65 dafb) led to a recovery in $\psi_{1}$ on control trees, but $\psi_{1}$ on RDI trees remained fairly stable at about $-1.7 \mathrm{MPa}$ (Fig. 4a). Predawn $\psi_{1}$ of

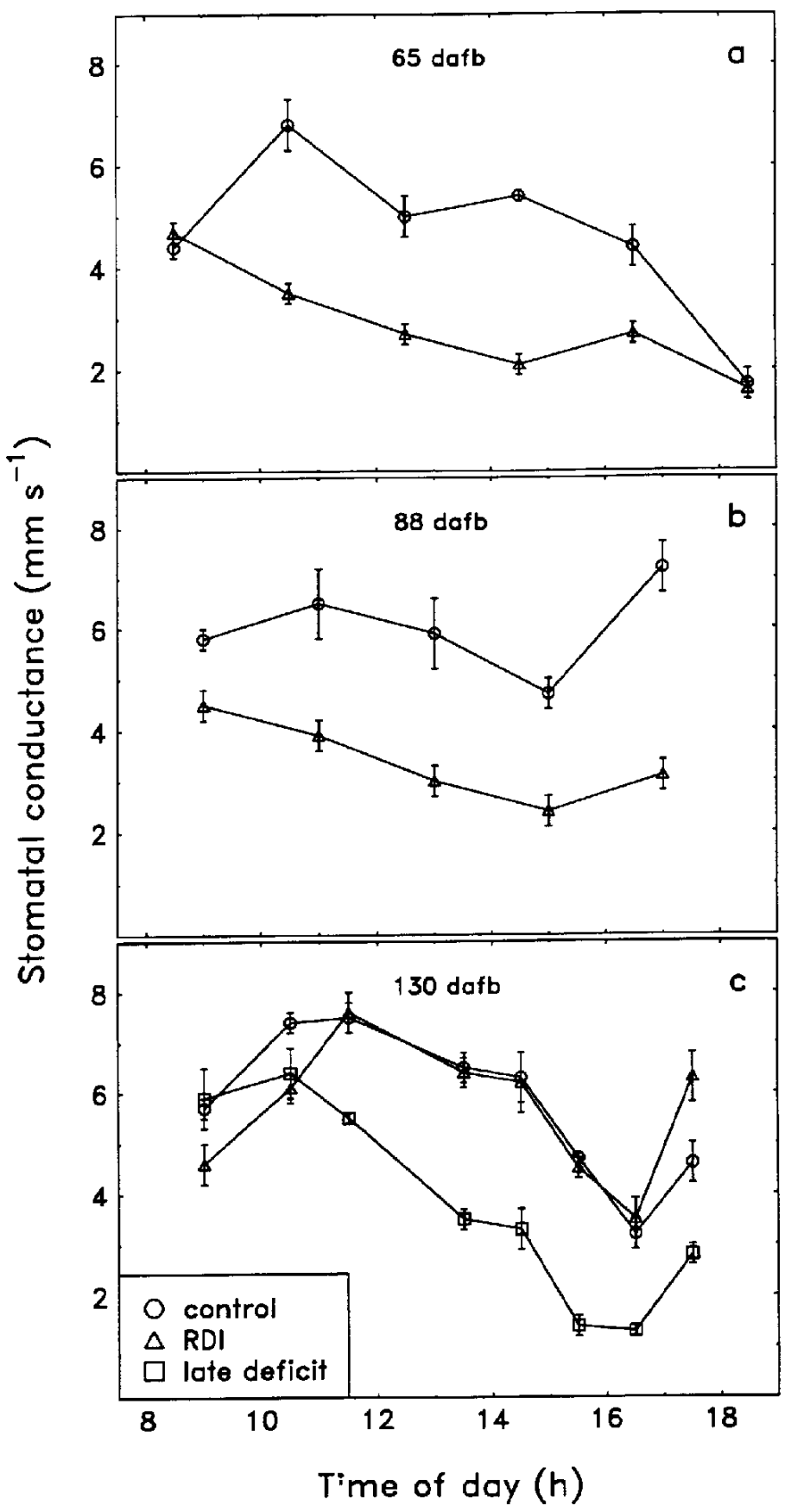

Fig. 3. Effect of irrigation regime on stomatal conductance of 'Hosui' Asian pear trees grown in lysimeters. Regulated deficit irrigation was applied from 42 to 114 days after full bloom (dafb) and late deficit irrigation from 126 to $158 \mathrm{dafb}$. Bars represent twice the SE of the means $(n \geq 7)$.

deficit-irrigated trees was substantially lower than the control on the last day of RDI (114 dafb, Fig. 4b). Control and RDI trees had lower minimum $\psi_{1}$ during this nearly cloud-free day. The $\psi_{1}$ of RDI trees was $\approx 0.9 \mathrm{MPa}$ lower than that of control trees for most of the day.

Initially, $\psi$, tended to be lower on RDI trees, even after trees were returned to full irrigation. One week after RDI was discontinued, $\psi_{1}$ of previously deficit-irrigated trees was $-2.0,-1.9$, and $-1.0 \mathrm{MPa}$ at solar noon, 15:30 and 17:30 HR, respectively. Control trees had significantly higher values of $-1.7,-1.7$, and $-0.7 \mathrm{MPa}$. Similar differences of 0.2 to $0.4 \mathrm{MPa}$ were also observed 2 weeks after rewatering (128 dafb). These results contrast with the re- 
sponse obtained with RDI on field-grown European pears (Chalmers et al., 1986).

The $\psi_{1}$ measurements during the first week of LDI indicated a $0.2 \mathrm{MPa}$ lower $\psi_{1}$ on LDI trees. However, no further measurements were taken during LDI. For the rest of the season, $\psi_{1}$ was similar for all treatments.

Shoot growth. Shoot extension in the first half of the season was significantly reduced using RDI (Fig. 5). Subsequently, summer pruning weights were substantially lower on RDI trees (Table 1). There were no significant differences between treatments in winter pruning weights (Table 1), indicating that regrowth of shoots after harvest was not affected by the previous deficit treatments. In our study, no water deficit was applied after harvest.

Fruit growth. RDI did not reduce final fruit weight or yield (Table 1). There was no difference in fruit volume or fruit growth rate between treatments up to the end of RDI (Fig. 6). In the final stages of RDI (110 to $115 \mathrm{dafb}$ ), the fruit growth rate on deficit-irrigated trees was lower than the control. During the first week after the return to full irrigation (115 to $122 \mathrm{dafb}$ ), fruit on RDI trees grew at a faster rate than fruit on control trees, thus compensating for any previous reduction in fruit growth. Thereafter, fruit growth rate was similar for the two treatments.

Water deficit in the later stages of fruit development reduced fruit growth rate and final fruit size (Fig. 6). The fruit growth rate of LDI fruit was significantly lower than that of control and RDI fruit during the final 3 weeks before harvest. Weight of labeled fruit was within $2 \mathrm{~g}$ of that estimated from volume measurements.

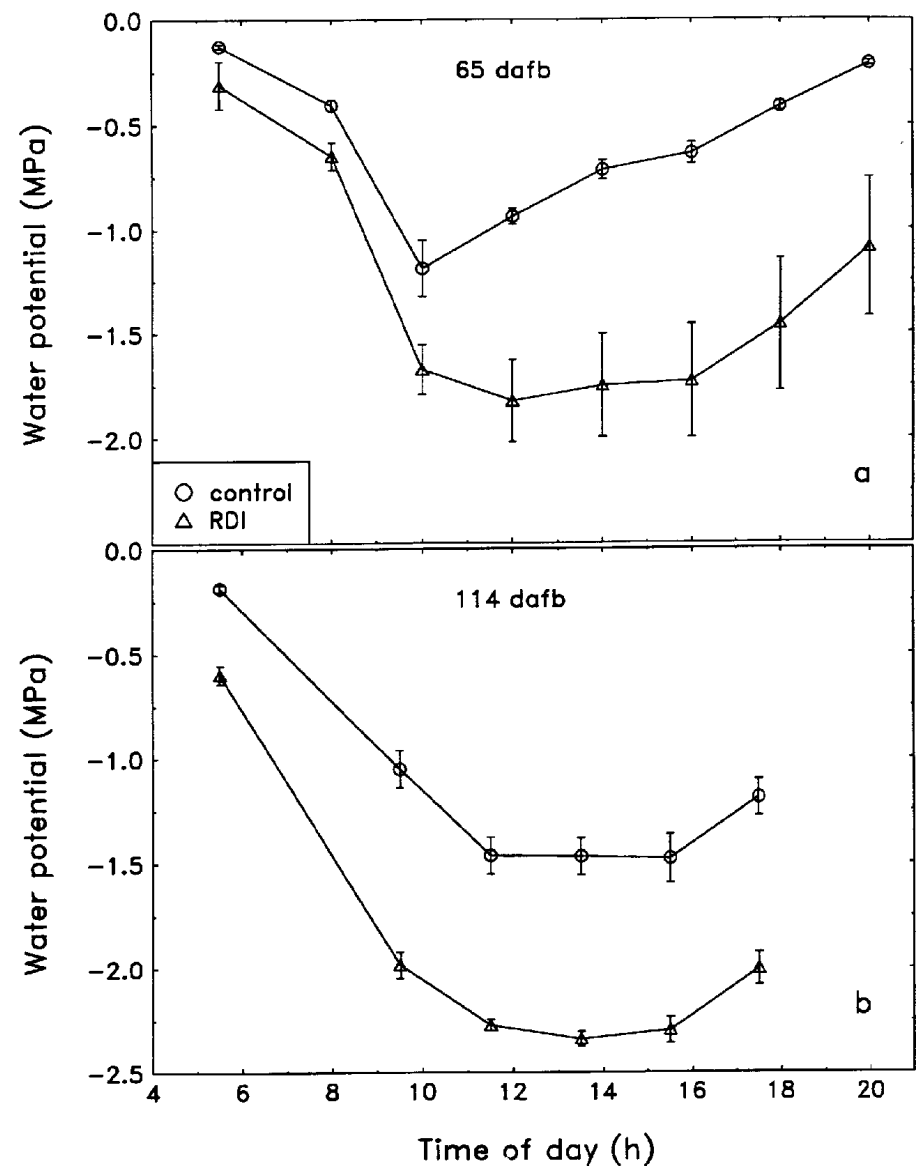

Fig. 4. Effect of irrigation regime on diurnal changes in leaf water potential of 'Hosui' Asian pear trees grown in lysimeters. Regulated deficit irrigation was applied from 42 to 114 days after full bloom (dafb). Bars represent twice the SE of the means $(n \geq 3)$.
However, after all fruit (labeled and nonlabeled fruit) had been harvested, neither mean fruit weight nor yield was significantly different between irrigation treatments (Table 1).

Return bloom. Field observations in Spring 1992 (Sept. to Oct.) showed flower density was very low on 'Hosui', 'Nijisseiki', and 'Shinseiki' Asian pear trees. In contrast, flowering was abundant on 'Kosui' Asian pears. RDI seemed to reduce further flower density of 'Hosui' trees growing in the lysimeters (observation only). There was also, however, a marked difference in flower density between trees within the RDI treatment. The two largest RDI trees had almost no flower buds at all ( $<10$ flower buds per tree), while the flower density of the third tree seemed unaffected by the water deficit when compared to the control. LDI did not seem to affect flowering (observation only).

\section{Discussion}

$W U$. This study shows that RDI can be successfully applied to Asian pears to control tree vigor without loss in fruit size and yield. It also provides a detailed insight of how tree transpiration is affected, not only during deficit irrigation, but also when full irrigation is resumed. In studies on RDI of peaches and European pears (Mitchell and Chalmers, 1982; Mitchell et al., 1989), reductions in irrigation volume of up to $33 \%$ have been reported. These savings, however, were calculated from irrigation volumes applied and the authors did not report how actual tree WU was altered. Although the duration of RDI in this experiment was comparatively long (72 days) and tree transpiration was $20 \%$ lower during RDI, accumulated seasonal WU was reduced by only $8 \%$ compared to control trees. This was because evaporative demand was relatively low during RDI, with peak transpiration occurring after RDI was discontinued.

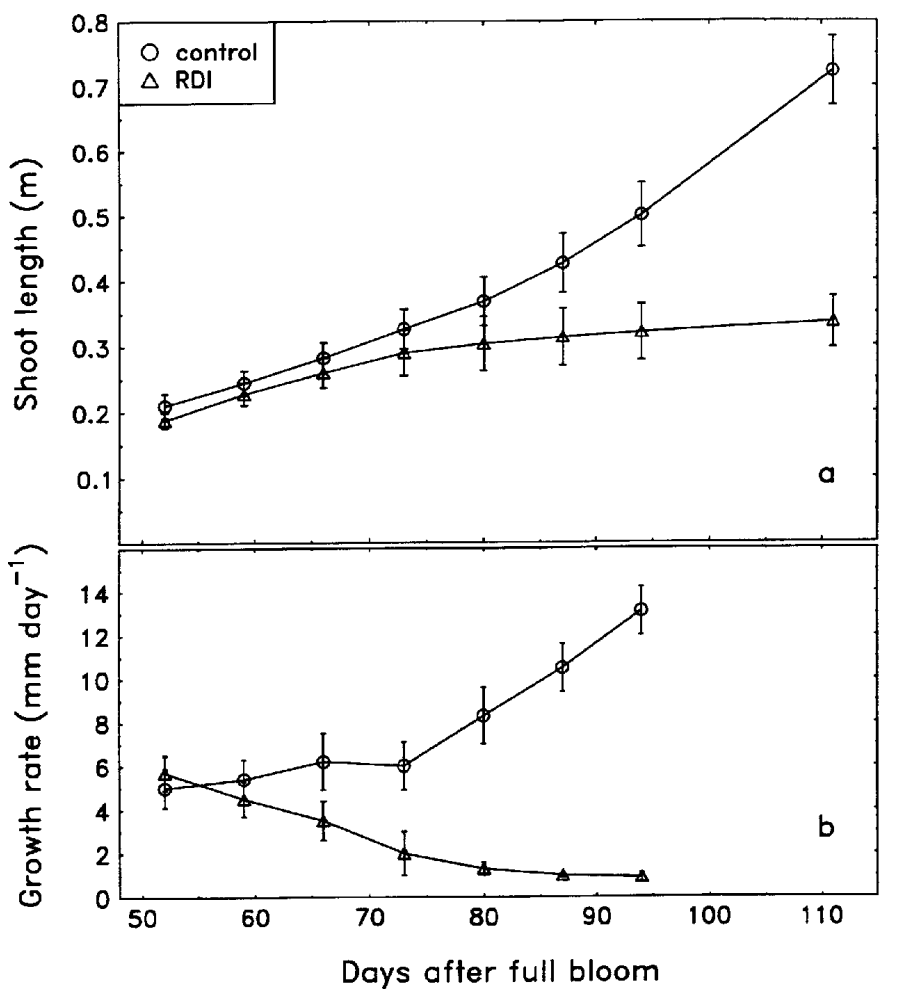

Fig. 5. Effect of irrigation regime on shoot extension of 'Hosui' Asian pear trees grown in lysimeters during the 1991-92 season. Regulated deficit irrigation was applied from 42 to 114 days after full bloom. Bars represent twice the SE of the means. 
Table 1. Effect of irrigation treatment on mean fruit weight, yield, and summer and winter pruning weights of 'Hosui' Asian pears.

\begin{tabular}{|c|c|c|c|c|}
\hline \multirow[b]{2}{*}{ Treatment $^{\mathrm{x}}$} & \multirow{2}{*}{$\begin{array}{c}\text { Fruit wt } \\
\qquad(\mathrm{g})\end{array}$} & \multirow{2}{*}{$\begin{array}{c}\text { Yield } \\
\left(\mathrm{kg} \cdot \mathrm{m}^{-2} \mathrm{CSA}\right)\end{array}$} & \multicolumn{2}{|c|}{$\begin{array}{c}\text { Pruning wt }{ }^{\mathrm{z}} \\
\left(\mathrm{kg} \cdot \mathrm{m}^{-2} \mathrm{CSA}^{\mathrm{y}}\right)\end{array}$} \\
\hline & & & Summer & Winter \\
\hline Control & $241 \pm 7.8^{\mathrm{w}}$ & $3.4 \pm 0.5$ & $345 \pm 61$ & $109 \pm 33$ \\
\hline RDI & $250 \pm 13.6$ & $3.4 \pm 0.2$ & $126 \pm 20$ & $76 \pm 37$ \\
\hline LDI & $238 \pm 7.3$ & $3.1+0.1$ & $\mathrm{na}^{\mathrm{v}}$ & $49 \pm 11$ \\
\hline Significance & NS & NS & NS & NS \\
\hline
\end{tabular}

zThis season's growth.

${ }^{\text {yCSA }}=$ canopy surface area.

${ }^{\mathrm{x}} \mathrm{RDI}=$ regulated deficit irrigation; $\mathrm{LDI}=$ late deficit irrigation.

${ }^{w}$ Mean \pm SE.

${ }^{\mathrm{v}}$ Not applicable. LDI trees were treated as control until 17 days after summer pruning.

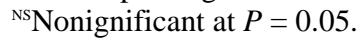

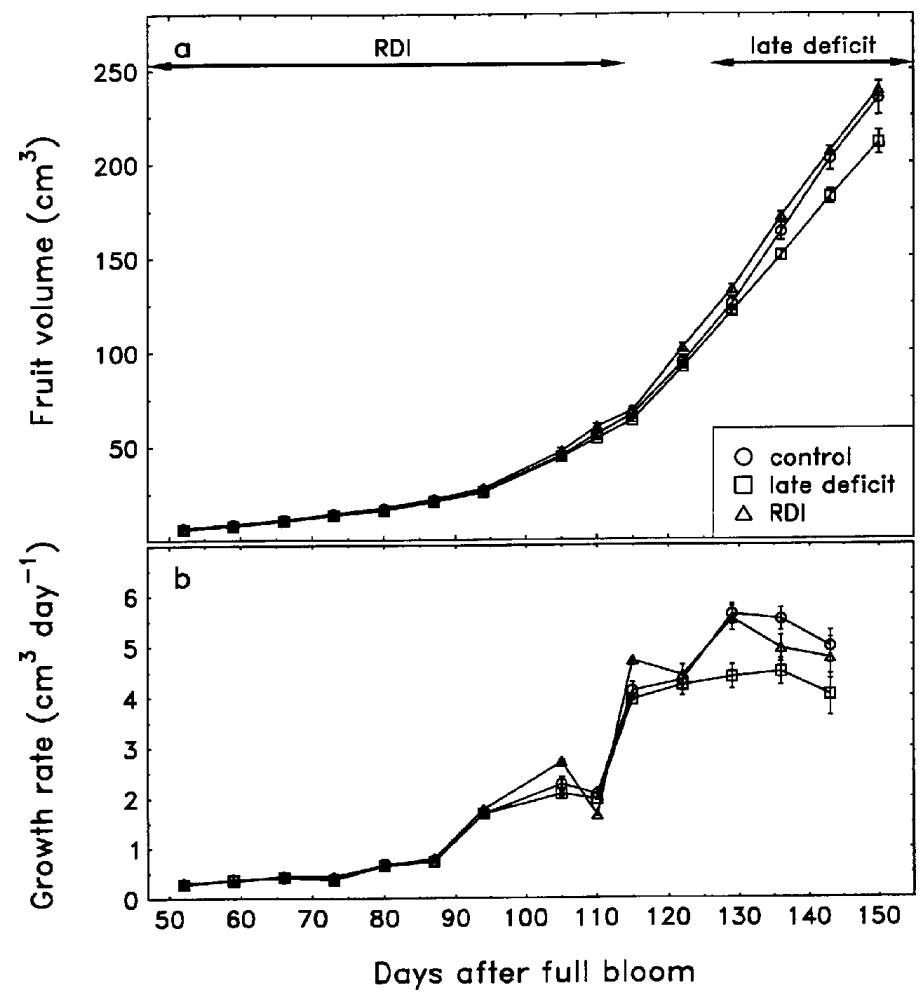

Fig. 6. Effect of irrigation regime on fruit size and fruit growth rate of 'Hosui' Asian pears grown in lysimeters. Regulated deficit irrigation was applied from 42 to 114 days after full bloom (dafb) and late deficit irrigation from 126 to $158 \mathrm{dafb}$. Bars represent twice the SE of the means.

Mechanisms of reducing $W U$. The main mechanism of reducing WU of deficit-irrigated Asian pear trees was a lower $\mathrm{g}_{\mathrm{s}}$, not a reduced leaf area. Indirect evidence is provided by the observation that WU of RDI trees was reduced before any effect of water deficit on shoot growth could be observed (Fig. 2 vs. Fig. 5). Further, using an energy-balance approach, it could be shown that the lower tree WU during early stages of RDI was caused by lower leaf $g_{s}$ measured on RDI trees (Caspari et al., 1993b). However, the reduction in vegetative growth during RDI would have caused a slightly lower total leaf area, which could have contributed to limiting WU at the end of RDI. On the other hand, summer pruning would have eliminated this difference in leaf area to a large extent.

LDI trees were irrigated like the control until the start of the treatment, when leaf areas were already fully developed. Vegeta- tive growth had ceased before the treatment commenced so that leaf areas remained unchanged during LDI. Thus, the lower WU of LDI trees can also be attributed to lower $\mathrm{g}_{\mathrm{s}}$ (Fig. 3c).

Changes in leaf areas due to reinitiated shoot growth after summer pruning were small and, as indicated by the current year's winter pruning weights (Table 1), not different between treatments. Total leaf areas measured at the end of the season were very similar for all treatments $\left(12.2,12.5\right.$, and $12.6 \mathrm{~m}^{2}$ for control, LDI, and RDI, respectively). When WU was calculated on a leaf-area basis for the months after rewatering (using above values), WU was $7 \%$ lower on RDI trees, with no differences between LDI and control trees. Therefore, the lower transpiration of RDI trees initially observed after full irrigation was resumed (Fig. 2) was not caused by a reduced leaf area but may be related to the lower $g_{s}$ measured during parts of the day. Lower values of $g_{s}$ during the first days after rewatering have also been reported for potted apple (Flore et al., 1985; Landsberg and Jones, 1981), peach (Tan and Buttery, 1982), and Asian pear trees (M.H. Behboudian, unpublished data). The $\mathrm{g}_{\mathrm{s}}$ of water-stressed peach seedlings rose for several days after rewatering, but recovered to only $70 \%$ of the fully watered control plants (Tan and Buttery, 1982).

Shoot growth. RDI reduced shoot extension and summer pruning weights of Asian pears, as previously shown for peaches (Chalmers et al., 1981; Li et al., 1989) and European pears (Mitchell et al., 1984, 1989). In contrast, LDI had no effect on shoot growth because it was applied at a time when shoot growth had already stopped. Winter pruning weights (Table 1) indicate that there was no treatment effect on late-season shoot growth, as previously observed for 'Bartlett' pears (Mitchell et al., 1986).

Fruit growth. Except for the last week of RDI, Asian pear fruit growth (Fig. 6) was not significantly depressed during RDI and, in this respect, was similar to the fruit growth of European pears (Mitchell et al., 1984). Mitchell et al. (1989) emphasized the importance of discontinuing RDI before the onset of rapid fruit growth. In their studies on European pears, they defined this time as when weekly fruit growth measurements indicated a mean fruit growth rate of $2 \mathrm{~cm}^{3} \cdot$ day $^{-1}$ compared to $1.5 \mathrm{~cm}^{3} \cdot \mathrm{day}^{-1}$ in the previous week. The decreased fruit growth rate of RDI fruit during the week before full irrigation (Fig. 6) indicates that the correct time was missed in our study, and RDI trees should have been rewatered one week earlier. From this and our previous fruit growth data (Caspari et al., 1993a) we conclude that water should be made readily available when fruit growth rate of 'Hosui' Asian pears increases to $2 \mathrm{~cm}^{3} \cdot \mathrm{day}^{-1}$. These results seem to agree with the report by Mitchell et al. (1989).

A water deficit during the final stages of fruit growth had no effect on mean fruit weight and yield of 'Cox's Orange Pippin' apples (Irving and Drost, 1987). In contrast, a late water deficit reduced fruit size of 'Granny Smith' apples (Lötter et al., 1985) and 'Merrill Sundance' peaches (Li et al., 1989). Early or late water deficit (similar to our RDI and LDI) had no deleterious effect on fruit growth of 'Nijisseiki' Asian pears (M.H. Behboudian, unpublished data). Measurements of fruit weight at harvest (Table 1) did not reflect the differences indicated by fruit volume measurements (Fig. 6). Nevertheless, the fruit growth measurements are unequivocal. They show that a less-severe water deficit than that imposed during RDI inhibited fruit growth by $17 \%$. While the experimental design was not sufficiently rigorous to confirm the statistical significance of this growth effect on yield, it is clear that, in practice, such a treatment would reduce yield and fruit grade.

Water relations. The differences in $\psi_{1}$ at dawn and midday observed during RDI are larger than differences of 0.05 and 0.3 $\mathrm{MPa}$, respectively, reported for 'Bartlett' pear (Chalmers et al., 
1986). According to $\psi_{1}$, plant water status improved when RDI trees were rewatered. The important difference to our study, however, is the fact that 'Bartlett' pear leaves of previously deficit-irrigated trees had a less-negative $\psi_{1}$ than the control after RDI was discontinued (Chalmers et al., 1986), while $\psi_{1}$ on Asian pears initially remained lower than the control.

The lower tree transpiration, lower $g_{s}$, and more-negative $\psi_{1}$ of RDI trees during the first 2 weeks after rewatering indicate that there was a lasting effect of RDI on tree water relations. Partial stomatal closure reduces water loss and, under conditions of ample water supply, leads to an improved plant water status. The fact that $\psi_{1}$ remained lower on rewatered RDI trees despite lower $\mathrm{g}_{\mathrm{s}}$, i.e., lower water loss, suggests a change in the total hydraulic conductance in the soil-plant pathway. Hydraulic conductance can be partitioned into soil, root, and stem components (Jones et al., 1985). As soil-water potential was not different, this lower $g_{s}$ may have been caused by a reduced water uptake or stem conductance.

Return bloom. RDI increased return bloom of European pears (Mitchell et al., 1984, 1986) and peaches (Li et al., 1989). In other studies, the level of flowering was not affected (Brun et al., 1985) or decreased by water deficits (Landsberg and Jones, 1981; Proebsting et al., 1989; Uriu, 1964). These different results may be caused by differences in the plant species or may be related to varying degrees and timings of water stress. A moderate water deficit may increase flowering in peach, but a severe deficit will decrease it (Johnson et al., 1992). Also, the sensitivity of the flower bud to water deficit changes during bud development (Kaufmann, 1972). Flower-bud production of peach was improved only when the water deficit was applied during the critical period of flowerbud induction (Li et al., 1989).

The differences in flower density between RDI trees may have been caused by differences in soil moisture between RDI lysimeters during the first weeks of RDI. The two trees that had almost no flowers in Spring 1992 depleted the soil water to $\approx 50 \%$ of pot capacity within 3 weeks. Soil-water content in the third RDI lysimeter, which contained a less-vigorous tree, declined more slowly, reaching $50 \%$ of pot capacity after 4 weeks more. During the last weeks of RDI, soil moisture was similar in all RDI lysimeters. These data suggest that the more-rapid decline in soil-water storage or the extended period of water deficit experienced by these RDI trees may have caused the reduction in return bloom.

\section{Conclusion}

When calculated over the entire season, RDI trees used $8 \%$ less water than well-watered control trees. Lower WU of deficit-irrigated trees was caused primarily by lower $g_{s}$, not by reduced leaf area. Shoot growth could be reduced without deleterious effect on fruit growth and yield when RDI was applied before rapid fruit growth commenced. In contrast, fruit growth was inhibited by a water deficit during the final weeks of fruit growth without any favorable effect on shoot growth. On the other hand, the reduction in return bloom caused by RDI is very important and suggests that more experiments are needed on RDI in Asian pears. These preliminary observations suggest that more care will be needed in the management of RDI if it can be developed for Asian pears.

\section{Literature Cited}

Brun, C.A., J.T. Raese, and E.A. Stahly. 1985. Seasonal response of 'Anjou' pear trees to different irrigation regimes. II. Mineral composition of fruit and leaves, fruit disorders, and fruit set. J. Amer. Soc. Hort. Sci. 110:835-840.

Campbell, G.S. and M.D. Campbell. 1982. Irrigation scheduling using soil moisture measurements: Theory and practice. Adv. Irr. 1:25-42.
Caspari, H.W., M.H. Behboudian, D.J. Chalmers, and A.R. Renquist. 1993a. The pattern of seasonal water use of Asian pears as determined by lysimeters and the heat-pulse technique. J. Amer. Soc. Hort. Sci. 118:562-569.

Caspari, H.W., S.R. Green, and W.R.N. Edwards. 1993b. Transpiration of well-watered and water-stressed Asian pear trees as determined by lysimetry, heat-pulse, and estimated by a Penman-Monteith model. Agr. For. Meteorol. 67:13-27.

Chalmers, D.J.,P.K. Andrews, K.M. Harris, E.A. Cameron, and H.W. Caspari. 1992. Performance of drainage lysimeters for the evaluation of water use by Asian pears. HortScience 27:263-265.

Chalmers, D.J., G. Burge, P.H. Jerie, and P.D. Mitchell. 1986. The mechanism of regulation of 'Bartlett' pear fruit and vegetative growth by irrigation withholding and regulated deficit irrigation. J. Amer. Soc. Hort. Sci. 111:904907.

Chalmers, D.J., P.D. Mitchell, and L. van Heek. 1981. Control of peach tree growth and productivity by regulated water supply, tree density, and summer pruning. J. Amer. Soc. Hort. Sci. 106:307-312.

Chalmers, D.J., B. van den Ende, and L. van Heek. 1978. Productivity and mechanization of the Tatura trellis orchard. HortScience 13:517-521.

Downton, W.J.S., W.J.R. Grant, and B.R. Loveys. 1987. Diurnal changes in the photosynthesis of field-grown grape vines. New Phytol. 105:71-80.

Durand, G. 1990. Effects of RDI on apple tree (cv. Royal Gala) growth, yield and fruit quality in a humid environment. $\mathrm{PhD}$ thesis. Massey Univ., Palmerston North, New Zealand.

Flore J.A., A.N. Lakso, and J.W. Moon. 1985. The effect of water stress and vapour pressure gradient on stomatal conductance, water use efficiency, and photosynthesis of fruit crops. Acta Hort. 171:207-218.

Higgs, K.H. and H.G. Jones. 1990. Response of apple rootstocks to irrigation in south-east England. J. Hort. Sci. 65:129-141.

Irving, D.E. and J.H. Drost. 1987. Effects of water deficit on vegetative growth, fruit growth and fruit quality in Cox's Orange Pippin apple. J. Hort. Sci. 62:427-432.

Johnson, R.S., D.F. Handley, and T.M. DeJong. 1992. Long-term response of early maturing peach trees to postharvest water deficits. J. Amer. Soc. Hort. Sci. 117:881-886.

Jones, H.G., A.N. Lakso, and J.P. Syvertsen. 1985. Physiological control of water status in temperate and subtropical fruit trees. Hort. Rev. 7:301-344.

Kaufmann, M.R. 1972. Water deficits and reproductive growth, p. 91--124. In: T.T. Kozlowski (ed.). Water deficit and plant growth. vol. 3. Academic Press, New York.

Landsberg, J.J. and H.G. Jones. 1981. Apple orchards, p. 419-469. In: T.T. Kozlowski (ed.). Water deficit and plant growth. vol. 6. Academic Press, New York.

Li, S.-H., J.-G. Huguet, P.G. Schoch, and P. Orlando. 1989. Response of peach tree growth and cropping to soil water deficit at various phenological stages of fruit development. J. Hort. Sci. 64:541-552.

Lötter, J. De V., D.J. Beukes, and H.W. Weber. 1985. Growth and quality of apples as affected by different irrigation treatments. J. Hort. Sci. 60:181-192. Mitchell, P.D. and D.J. Chalmers. 1982. The effects of reduced water supply on peach tree growth and yields. J. Amer. Soc. Hort. Sci. 107:853-856.

Mitchell, P.D., D.J. Chalmers, P.H. Jerie, and G. Burge. 1986. The use of initial withholding of irrigation and tree spacing to enhance the effect of regulated deficit irrigation on pear trees. J. Amer. Soc. Hort. Sci. 111:858-861.

Mitchell, P.D., P.H. Jerie, and D.J. Chalmers. 1984. The effects of regulated water deficits on pear tree growth, flowering, fruit growth, and yield. J. Amer. Soc. Hort. Sci. 109:604-606.

Mitchell, P.D., B. van den Ende, P.H. Jerie, and D.J. Chalmers. 1989. Responses of 'Bartlett' pear to withholding irrigation, regulated deficit irrigation, and tree spacing. J. Amer. Soc. Hort. Sci. 114:15-19.

Proebsting, E.L., P.H. Jerie, and J. Irvine. 1989. Water deficit and rooting volume modify peach tree growth and water relations. J. Amer. Soc. Hort. Sci. 114:368-372.

SAS Institute. 1985. SAS/STAT guide for personal computers. version 6. SAS Institute, Cary, N.C.

Sharma, M.L. 1985. Estimating evapotranspiration. Adv. Irr. 3:213-281.

Tan, C.S. and B.R. Buttery. 1982. The effect of soil moisture stress to various fractions of the root system on transpiration, photosynthesis, and internal water relations of peach seedlings. J. Amer. Soc. Hort. Sci. 107:845-849.

Uriu, K. 1964. Effect of postharvest soil moisture depletion on subsequent yield of apricots. Proc. Amer. Soc. Hort. Sci. 84:93-97. 